SUBJECT AREAS:

NEUROSCIENCE

BIOTECHNOLOGY

Received

5 December 2013

Accepted

18 March 2014

Published

2 April 2014

Correspondence and requests for materials should be addressed to D.-Y.Z.

(dongyizhang@nudt. edu.cn) or S.-P.L.

(liangsp@hunnu.edu.

$\mathrm{cn}$ )

* These authors contributed equally to this work.

\title{
Screening for Voltage-Gated Sodium Channel Interacting Peptides
}

\author{
Er Meng ${ }^{1 *}$, Tian-Fu Cai ${ }^{2 *}$, Hui Zhang ${ }^{2}$, Si Tang ${ }^{2}$, Meng-Jie Li ${ }^{2}$, Wen-Ying Li' ${ }^{1}$ Peng-Fei Huang ${ }^{2}$, Kai Liu ${ }^{2}$, \\ Lei Wu', Ling-Yun Zhu', Long Liu', Kuan Peng ${ }^{3}$, Xian-Dong Daii ${ }^{4}$, Hui Jiang ${ }^{4}$, Xiong-Zhi Zeng ${ }^{2}$, \\ Song-Ping Liang ${ }^{2} \&$ Dong-Yi Zhang'
}

'State Key Laboratory of High Performance Computing, Research Center of Biological Information, National University of Defense Technology, Changsha, Hunan 410073, China, ${ }^{2}$ Key Laboratory of Protein Chemistry and Developmental Biology of the Ministry of Education, College of Life Sciences, Hunan Normal University, Changsha, Hunan 410081, China, ${ }^{3}$ Core Facilities of Biotechnology, Central South University of Forestry and Technology, Changsha, Hunan 410004, China, ${ }^{4}$ Beijing Institute of Pharmaceutical Chemistry, Beijing 102205, China.

The voltage-gated sodium channel (VGSC) interacting peptide is of special interest for both basic research and pharmaceutical purposes. In this study, we established a yeast-two-hybrid based strategy to detect the interaction(s) between neurotoxic peptide and the extracellular region of VGSC. Using a previously reported neurotoxin JZTX-III as a model molecule, we demonstrated that the interactions between JZTX-III and the extracellular regions of its target $\mathrm{hNa}_{\mathrm{v}} \mathrm{l} .5$ are detectable and the detected interactions are directly related to its activity. We further applied this strategy to the screening of VGSC interacting peptides. Using the extracellular region of $\mathrm{hNa}_{\mathrm{v}} 1.5$ as the bait, we identified a novel sodium channel inhibitor SSCM-1 from a random peptide library. This peptide selectively inhibits $\mathrm{hNa}_{\mathrm{v}} 1.5$ currents in the whole-cell patch clamp assays. This strategy might be used for the large scale screening for target-specific interacting peptides of VGSCs or other ion channels.

$\Lambda$ mong various types of ion channels, voltage-gated sodium channels (VGSCs) are responsible for the genesis and propagation of action potential, by which the responses of nociceptors to stimuli are encoded. The VGSCs are therefore considered ideal targets for the development of pain therapeutics ${ }^{1,2}$. For decades, small molecules such as lidocaine and mexiletine targeting VGSCs, although not specifically, have been widely used in the clinical treatment of pain ${ }^{3}$. Recently, biologicals such as peptides and antibodies were proposed to be the next generation of pain relief drug leads. Compared with small chemical molecules, peptides demonstrate a greater potential for ion channel targeting selectivity, whereas the lower selectivity over the sub-types of VGSCs or other ion channels of small chemical molecule might be responsible for their clinical side effects ${ }^{4}$.

Venom peptides are considered as an invaluable source of natural products for drug discovery. Several peptide toxins isolated from venoms of scorpion, spider, and cone snails were demonstrated to be able to interact with VGSCs and might be further developed into pain relief drugs ${ }^{1,5,6}$. Six venom peptides or protein derivatives became FDA-approved drugs and more are in clinical trials or various stages of preclinical development ${ }^{7}$. Although the pursuit of VGSC blockers is an exciting prospect, the progress of obtaining VGSCs blockers from venoms is somehow disappointing. For example, out of the conservatively estimated more than 10 million bioactive peptides that might be present in the spider venoms, only 62 peptides were identified to be VGSCs interacting peptides, and some of them target more than one type of channels ${ }^{8}$.

According to the previously published works and our own experiences, the isolation and characterization of a VGSC or other ion channel interacting peptide from venoms usually consists of four typical procedures: the collection of crude venoms, the isolation and purification of single component/peptide, the analysis of biochemical characterization of the peptide, and the physiological characterization of the peptide. The biochemical isolation and purification of single peptide from the crude venom requires not only a sufficient amount of crude venom, but also the equipment, reagents, skills and experiences, time, and sometimes even luck [some venoms might contain as many as 1,000 different kinds of peptides and proteins $]^{9}$. The physiological activity of a purified peptide could be estimated by different in vivo assays by using animals, insects, or cultured cells. However, to determine its molecular target(s) could be a struggle. There are too many possible targets: receptors, various kinds of ion channels, and different sub-types of a certain ion channel. In summary, the current approaches for the isolation and characterization of ion channels interacting peptides from venoms are low throughput. Moreover, 
using the current approaches, we are isolating ion channel interacting peptide by chance or with luck, since it is hard to predict what kind of interacting peptide can be isolated from a venom mixture. We initiated our work reported here from two questions: For a given peptide or toxin, is there a high throughput approach to predict its potential interaction site(s)? Targeting a given voltage-gated sodium channel, is there a high throughput approach to screen for its interacting peptide(s)?

\section{Results}

Mapping the interaction sites of JZTX-III on VGSCs. It is commonly recognized that the peptide regulates the VGSC function through its direct or indirect interaction(s) with the target molecule. It is therefore reasonable to assume that by detecting the interaction(s) between peptides and VGSC proteins, we would be able to predict whether a peptide could be a VGSC inhibitor or activator. Yeast-two-hybrid approach developed in 1989 provides a powerful tool for the high throughput study of protein-protein interaction(s) in vivo and has been widely used in searching for protein-protein interactions in many research works, even in new drug discovery ${ }^{10,11}$. A major concern of using yeast-two-hybrid method to study the interaction(s) between peptides and VGSCs is the conformation issue. A functional voltage-gated sodium channel is composed of a large pore-forming $\alpha$ subunit $(220 \sim 260 \mathrm{kDa})$ and one or more auxiliary $\beta$ subunit(s) $(33 \sim 36 \mathrm{kDa})$. Most of the previously reported VGSC interacting peptides bind to the $\alpha$ subunits. Structurally, a VGSC $\alpha$ subunit is comprised of four homologous domains (DI-DIV). In each domain, there are six transmembrane segments (S1-S6) connected by both intracellular and extracellular regions ${ }^{12,13}$. The maintenance of the natural conformation of a VGSC requires the interactions between the VGSC protein and the cell membrane. In a yeast-two-hybrid assay, the natural conformation of a full length VGSC could be completely disturbed when expressed in the cytoplasm of the yeast cells without the assistant of cell membrane. Although it is not difficult to imagine that an extraneous peptide could bind to the target VGSC at its extracellular regions, could this kind of interaction be maintained by the extracellular region taken out of the full-length context and detected by yeast-two-hybrid assay?

We chose jingzhaotoxin-III (JZTX-III), a neurotoxic peptide isolated from the spider venom, as a model molecule to address this question. JZTX-III specifically blocks human $\mathrm{Na}_{\mathrm{v}} 1.5\left(\mathrm{hNa}_{\mathrm{v}} 1.5\right)$ and has almost no effect on $\mathrm{hNa}_{\mathrm{v}} 1.7$ at $1 \mu \mathrm{M}$. In a previous report, it was demonstrated that the DII/S3-S4 extracellular region of $\mathrm{hNa}_{\mathrm{v}} 1.5$ is critical to JZTX-III's inhibitory activity ${ }^{14}$. Is it possible that the DII/ S3-S4 region alone interacts with JZTX-III and could such an interaction be detected in a yeast-two-hybrid assay? In our experiments, JZTX-III was expressed in fusion with the DNA binding domain (DBD) of Gal4 and the S3-S4 regions from the four homologous domains of $\mathrm{hNa}_{\mathrm{v}} 1.5$ or $\mathrm{hNa}_{\mathrm{v}} 1.7$ were expressed in fusion with the activation domain (AD) of Gal4 in yeast, respectively (Supplementary Table S1). As summarized in Table 1, the interactions between JZTX-III and the S3-S4 extracellular regions of $\mathrm{hNa}_{\mathrm{v}} 1.5$ or $\mathrm{hNa}_{\mathrm{v}} 1.7$ could be detected by yeast-two-hybrid assay. More interestingly, the interaction pattern of $\mathrm{hNa}_{\mathrm{v}} 1.5$ with JZTX-III was different from that of the $\mathrm{hNa}_{\mathrm{v}} 1.7$.

In addition to the expected interaction between JZTX-III and DII/ S3-S4 region, interactions between JZTX-III and S3-S4 regions of other domains of $\mathrm{hNa}_{\mathrm{v}} 1.5$ were also detected. Do these interactions contribute to JZTX-III's physiological activity? To address this question, we generated a series of $\mathrm{hNa}_{\mathrm{v}} 1.5$ and $\mathrm{hNa}_{\mathrm{v}} 1.7$ chimeras (Fig. 1; see also Supplementary Table S2). These chimeras were expressed in the cultured human embryonic kidney 293 (HEK293) cells and the corresponding sodium currents were detected by whole-cell patch clamp experiments. In a loss-of-function assay, as shown in panels $\mathrm{A}$ and $\mathrm{C}$ of Fig. 2, $\mathrm{hNa}_{\mathrm{v}} 1.5$ chimeras lost its sensitivity to JZTX-III
Table 1 | Detected interactions between JZTX-III and the S3-S4 extracellular regions

\begin{tabular}{lcc} 
Extracellular region & JZTX-III vs hNa 1.5 & JZTX-III vs $h N a_{v} 1.7$ \\
\hline DI/S3-S4 & + & + \\
DII/S3-S4 & + & N.D. \\
DIII/S3-S4 & + & N.D. \\
DIV/S3-S4 & + & N.D. \\
\hline
\end{tabular}

The symbol " +" represents a detectable interaction. N.D. (not detected).

inhibition when its S3-S4 fragments were replaced by those from $\mathrm{hNa}_{\mathrm{v}}$ 1.7. On the other hand, when the S3-S4 fragments were replaced by those from $\mathrm{hNa}_{\mathrm{v}} 1.5, \mathrm{hNa}_{\mathrm{v}} 1.7$ chimeras gained partial sensitivity to JZTX-III (Fig. 2, panels B and C). Moreover, when all the three S3-S4 fragments were replaced, the affinity to JZTX-III of $\mathrm{hNa}_{\mathrm{v}} 1.5$ chimera became almost identical to that of the wild type $\mathrm{hNa}_{\mathrm{v}} 1.7$, and vice versa. The dose-response curves of JZTX-III inhibiting several chimeras were also shown in Fig. 2D, and the estimated $\mathrm{IC}_{50}$ values of JZTX-III were $0.297,1.047,0.736$, and $0.476 \mu \mathrm{M}$ for wild type $\mathrm{hNa}_{\mathrm{v}} 1.5, \mathrm{~m} 1.5-2, \mathrm{~m} 1.7-1$, and $\mathrm{m} 1.7-4$ channels, respectively. The $\mathrm{IC}_{50}$ value for other chimeras could not be accurately calculated, but our data indicate that it is at least $>10 \mu \mathrm{M}$ (data not shown).

These results demonstrated that in addition to the interaction between DII/S3-S4 region of $\mathrm{hNa}_{\mathrm{v}} 1.5$ and JZTX-III, which was proposed in a previous study and confirmed here, the interactions of DIII and DIV S3-S4 regions of $\mathrm{hNa}_{\mathrm{v}} 1.5$ with JZTX-III detected by the yeast-two-hybrid assay in this study also contribute to its sensitivity to JZTX-III. With these results, it would be safe to propose that the analysis of interaction profiles of a given peptide with the extracellular regions of the VGSCs might provide valuable clues to the defining of its target(s). The fact that the replacement of $h \mathrm{Na}_{\mathrm{v}} 1.7$ 's extracellular regions with those from $\mathrm{hNa}_{\mathrm{v}} 1.5$ alters its sensitivity to extraneous interacting peptide, at least in the JZTX-III case is also of potential applications. We have noticed that not all VGSCs currents could be functional reconstructed in cultured cells, for example, there is no reconstructed $\mathrm{Na}_{\mathrm{v}} 1.9$ current reported thus far. However, as we replaced the extracellular regions of $\mathrm{hNa}_{\mathrm{v}} 1.5$ (using $\mathrm{hNa}_{\mathrm{v}} 1.5$ as the scaffold) with those from $\mathrm{hNa}_{\mathrm{v}} 1.9$ (i.e., the S1-S2 region or S3-S4 region, respectively), we were easily able to measure the sodium currents $(0.5 \sim 3 \mathrm{nA})$ of some chimeric channels in cultured HEK293 cells in whole-cell patch clamp assays (Supplementary
hNa 1.5 DII hNa 1.7 DII

M1.5-1 DII

M1.7-1 DII

$h_{N a} 1.5$ DIII hNa 1.7 DIII

M1.5-2 DIII M1.7-2 DIII

hNa 1.5 DIV hNa 1.7 DIV M1.5-3 DIV M1.7-3 DIV

hNa 1.5 DII $\mathrm{rNa}_{\mathrm{v}} 1.4$ DII M1.5-5 DII M1.4-1 DII
S3 ILSLMELGLSRMSNLSVLRSFRLL
TLSLVELFLADVEGLSVLRVLRSF
ILSLMELGLSDVEGLSVLRSFRLL
TLSLVELFLARMSNLSVLRVLRSF

SLVSLVANTLGFAEMGPIKSLRTL SLVTLVANTLGYSDLGPIKSLRTL SLVSLVANTLGYSDLGPIKSLRTI SLVTLVANTLGFAEMGPIKSLRTL
Figure $1 \mid$ Defining the motifs in chimeras. The transplanted sequence in each chimera is show in colors. 
A
WT-1.5

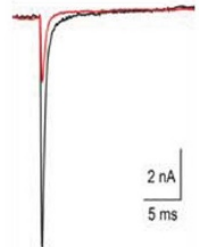

M1.5-4

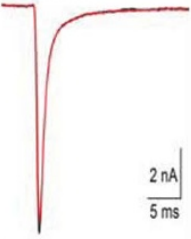

M1.5-1

M1.5-2

M1.5-3
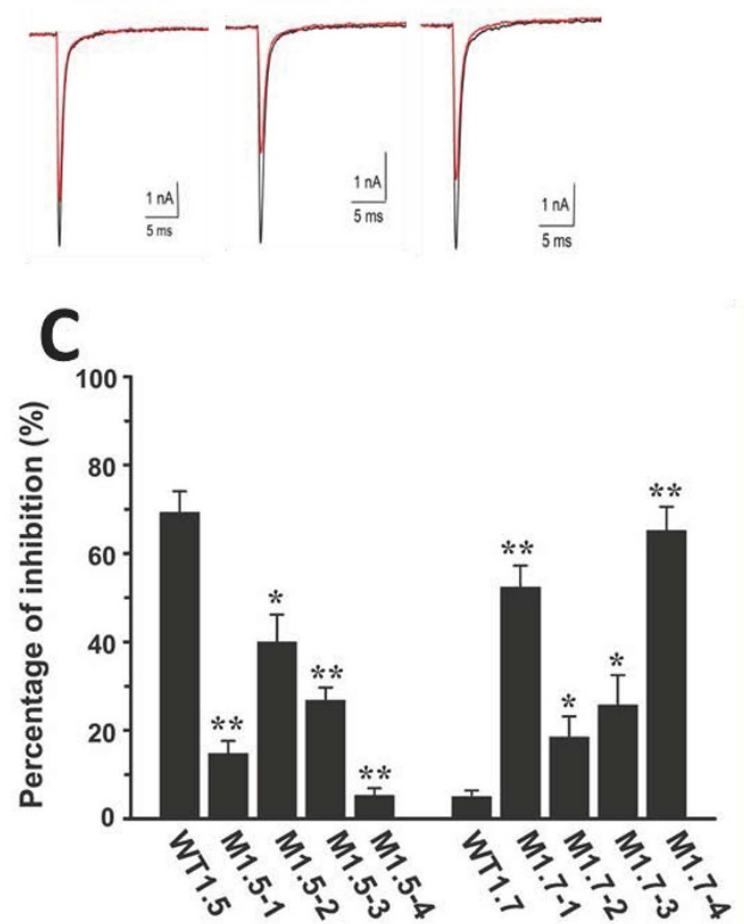

B
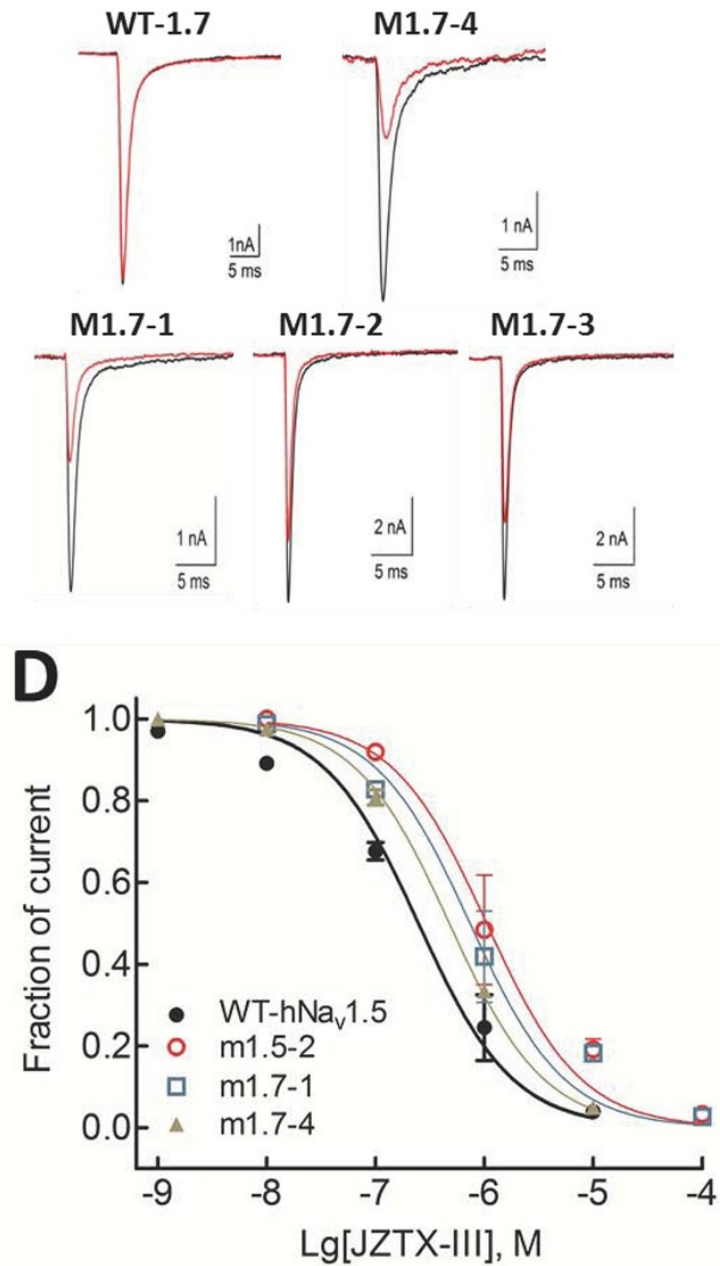

Figure $2 \mid$ Loss- or gain-of-function analysis of $\mathrm{hNa}_{\mathrm{v}} 1.5$ and $\mathrm{hNa}_{\mathrm{v}} 1.7$ chimeras. The wild type (WT) or chimeric VGSC currents were recorded before (black trace) and after (red trace) the application of JZTX-III. Panel A, inhibition of $1 \mu \mathrm{M}$ JZTX-III on WT-hNa 1.5 and chimeric hNa $_{\mathrm{v}} 1.5$ currents with S3-S4 fragments replaced by those from $\mathrm{hNa}_{\mathrm{v}}$ 1.7. M1.5-1, M1.5-2, M1.5-3, and M1.5-4 represent chimeras with the S3-S4 fragments of DII, DIII, DIV, and all three domains (DII + DIII + DIV) of $\mathrm{hNa}_{\mathrm{v}} 1.5$ replaced by those from $\mathrm{hNa}_{\mathrm{v}} 1.7$, respectively. Panel B, inhibition of $1 \mu \mathrm{M}$ JZTX-III on $\mathrm{hNa}_{\mathrm{v}} 1.7$ currents, the naming of the chimeras followed the same rules as for the $\mathrm{hNa}_{\mathrm{v}} 1.5$ chimeras. Panel C, quantitation of the inhibition percentage of JZTX-III $(1 \mu \mathrm{M})$ on chimeras' currents. *, $\mathrm{p}<0.05$; $^{* *}, \mathrm{p}<0.001$ significance between WT and chimeric channels. Panel D, concentration-response inhibitory curves of JZTX-III. Data points (mean \pm S.E., each from $3-5$ cells).

Table S3). We would suggest that these chimeric sodium channel be utilized in the finding of $\mathrm{Na}_{\mathrm{v}} 1.9$ interacting peptides, although voltage-gated potassium channel chimeras approach were proposed previously $^{15}$.

Screening the random peptide library. After demonstrating that the interaction(s) between peptides and extracellular regions of VGSCs can be detected by this strategy and some the interaction(s) detected are physiologically relevant, we further carried out experiments using yeast-two-hybrid method to search for the interacting peptides of a given voltage-gated sodium channel.

In a typical screening of cofactors of a given protein using yeasttwo-hybrid approach, a DNA library or pool is usually required. At least three types of DNA libraries are optional for the screening for VGSC interacting peptides, including a cDNA library constructed using the tissues of venomous animals, a saturated-mutation library based on a known toxic peptide, or a random peptide library from "nowhere". The cDNA library of venomous animals seemed to be a good choice since many researchers considered the natural venoms might be the valuable source of ion channel blockers. However, previous study demonstrated that the coding region of a piece of cDNA presented in a venomous animal tissue cDNA library usually consist of not only the matured peptide, but also the signal peptide and the pro-peptide ${ }^{16-18}$. The existence of such non-matured peptide fragments might interfere with the yeast-two-hybrid assay and yield the false-positive or false-negative results. Obtaining several bioactive peptides by either saturated or site-directed mutating some residues of a known toxin is almost guaranteed. Therefore a saturatedmutation library based on a known toxin backbone is a safer choice yet may be too conservative in our view. We generated a random peptide library by inserting 30 continuous random nucleotides following the $\mathrm{DBD}$ coding sequence in the $\mathrm{pGADT}_{7}$ plasmid by PCR. In a $10^{5}$ scale screening using the DII/S3-S4 region of $\mathrm{hNa}_{\mathrm{v}} 1.5$ as the bait, we identified a DNA sequence that encodes a peptide containing 26 amino acid residues which was able to interact with $\mathrm{hNa}_{\mathrm{v}} 1.5$ in vivo. The deduced amino acid sequence of this peptide is $\mathrm{NH}_{2}-$ MKYKNSTRVGIDTGSIELELQMNRRY-COOH.

This peptide was then chemically synthesized and applied to the electrophysiological assay of its bioactivity on $\mathrm{hNa}_{\mathrm{v}} 1.5$. As shown in panel A of Fig. 3, in a whole-cell patch-clamp assay, it inhibited wild 


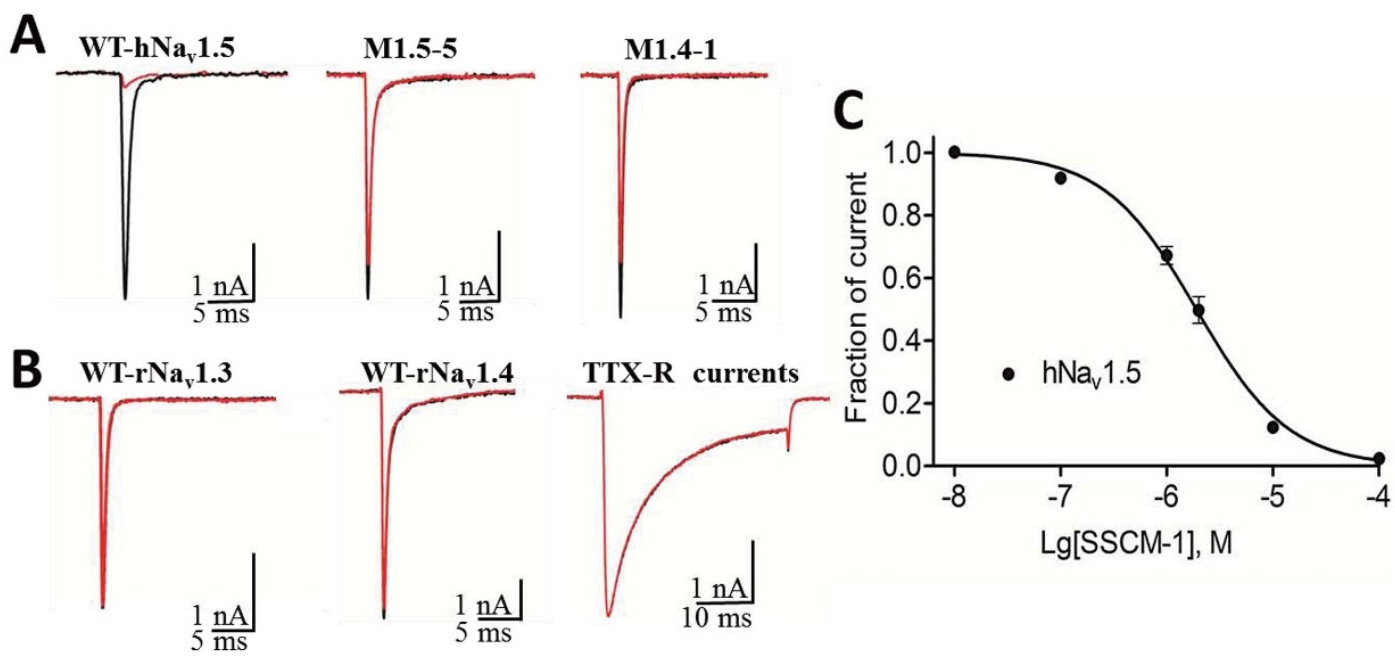

Figure 3 Effects of peptide SSCM-1 on VGSCs. The wild type (WT) or chimeric VGSC currents were recorded before (black trace) and after (red trace) the application of SSCM-1. Panel A, WT-hNa 1.5 currents were inhibited over $90 \%$ at $10 \mu \mathrm{M}$ SSCM-1, but SSCM-1 could only inhibit about $15 \%$ chimera M1.5-5 currents at $50 \mu \mathrm{M}$. SSCM-1 could not inhibit TTX-R currents expressed on DRG cells (containing $200 \mu \mathrm{M}$ TTX) at $10 \mu \mathrm{M}$. Panel B, WT$\mathrm{rNa}_{\mathrm{v}} 1.3$ and WT-rNa 1.4 currents almost no detectable inhibitory effect was observed at $50 \mu \mathrm{M}$ SSCM-1. Chimera M1.4-1 currents could be inhibited $15 \%$ by SSCM- 1 at $50 \mu$ M. Panel C, concentration-response inhibitory curves of SSCM- 1 on $\mathrm{hNa}_{\mathrm{v}} 1.5$ currents. Data points (mean \pm S.E., each from $3-5$ cells).

type $\mathrm{hNa}_{\mathrm{v}} 1.5$ currents over $90 \%$ at $10 \mu \mathrm{M}$. It was therefore named Screened-Sodium-Channel-Interacting peptide-1 (SSCM-1). The selectivity of VGSC isoforms was also observed since SSCM-1 has subtle inhibitory activity on $\mathrm{rNa}_{\mathrm{v}} 1.3, \mathrm{rNa}_{\mathrm{v}} 1.4$, or TTX-R currents as shown in Fig. 3B. To confirm that its inhibitory effect on $\mathrm{hNa}_{\mathrm{v}} 1.5$ is due to its interaction with the DII/S3-S4 region of $\mathrm{hNa}_{\mathrm{v}} 1.5$, the loss or gain-of-function assays were performed (Fig. 1 and Supplementary Table S2). As shown in Fig. 3A, in a loss-of-function assay, it was demonstrated that SSCM-1 had almost no effect on the chimeric $\mathrm{hNa}_{\mathrm{v}} 1.5$ currents with its DII/S3-S4 region replaced by that of $\mathrm{rNa}_{\mathrm{v}} 1.4$ (M1.5-5). On the other hand, when the DII/S3-S4 region of $\mathrm{rNa}_{\mathrm{v}} 1.4$ region was replaced by that of $\mathrm{hNa}_{\mathrm{v}} 1.5$, a detectable inhibitory effect of SSCM-1 over the resulted chimeric $\mathrm{rNa}_{\mathrm{v}} 1.4(\mathrm{M} 1.4-1)$ currents was observed. In Fig. 3C, Hill logistic equation fits of the dose-response curves indicated that the $\mathrm{IC}_{50}$ values yielded approximately was $2.88 \mu \mathrm{M}$ on wild-type $\mathrm{hNa}_{\mathrm{v}} 1.5$.

\section{Discussion}

The primary objective of the present study was to establish a highthroughput method to screen the given VGSC interacting peptide(s). Using a random peptide library and yeast-two-hybrid assays, we have succeeded in identifying a specific $\mathrm{hNa}_{\mathrm{v}} 1.5$ inhibitor SSCM-1. A homologous search showed that SSCM-1 has no significant similarity with any previously known peptides. Compared with other toxins isolated from natural venoms targeting VGSCs, SSCM-1 has no cysteine residue in its primary sequence and forms no disulfide bridge. It was claimed that after thousands of millions of years of evolution, the animal venoms contain most optimized toxins that can be used as drug model molecules for pharmaceutical purposes. We have no doubt of the power of evolution yet have noticed that in the nature, venomous animals developed their venoms in a most effective way for survival, they are preferably multifunctional-targeting more targets to adapt for the evolution of prey ${ }^{19}$. However, one of the primary considerations of whether a peptide could be developed to a potential drug is its selectivity, and highly selectivity is preferred for drug development. After decades of struggle, less than $1 \%$ of the peptides or proteins were isolated and partially characterized from natural developed venoms, even less were demonstrated to have potential pharmaceutical values ${ }^{8,9,20}$. Besides the lack of highly effective research tools, could the nature of the natural venoms be an intrinsic problem?
Theoretically, a peptide composed of 26 amino acid residues has $20^{26}$ different possible sequences. The number of possible existed peptides or proteins would increases in an exponential way if a peptide or protein contains more amino acid residues. A random peptide library obviously provides much more candidates for drug discovery or other purposes, as long as a high throughput screening tool is available. Practically, the yeast-two-hybrid approach could be used to screen a library with a complexity up to $10^{7}$, more efficient screening tools need to be developed to make full use of the random peptide libraries. Nevertheless, the finding of SSCM-1 provides a practical example for the screening of bioactive peptides targeting a given VGSC protein.

In conclusion, using the extracellular region of a given voltagegated sodium channel protein as a bait, the yeast-two-hybrid technology could be used to screen for specific interacting peptide(s) of the target protein from a laboratory constructed proper peptide library. Based on the fact that many voltage-gated ion channels including potassium channels, sodium channels, and calcium channels possessing similar structures ${ }^{13,21,22}$, our strategy may provide a high throughput solution to the identification of novel interacting peptides at these ion channels, which would facilitate the in depth study of ion channel function and the development of new bioactive drugs targeting on these ion channels.

\section{Methods}

Materials. Used for yeast two hybrid assays, MATCHMAKER GAL4 Two-Hybrid System 3 was purchased from Clontech (Mountain View, CA, USA). KOD-PlusDNA Polymerase which was employed to site-directed mutation or chimera assays was purchased from TOYOBO (Osaka, Japan). All the restriction enzymes used for molecular cloning assays were purchased from Fermentas (Burlington, ON, Canada) if not otherwise noted. The synthesis of non-random primers and DNA sequencing were performed by Sangon (Shanghai, China). The synthesis of random primers was performed by sbsgene (Shanghai, China). Peptide JZTX-III was purified as previously described $^{23}$. Peptide SSCM-1 was obtained by chemical synthesis. If no specially noted, all the chemicals were purchased from Sigma (St. Louis, MO, USA).

Yeast-two-hybrid assay. All the data of toxin and VGSCs are downloaded from UniProtKB/Swiss-Prot database [accession P08104 for $\mathrm{rNa}_{\mathrm{v}} 1.3, \mathrm{P} 15390$ for $\mathrm{rNa}_{\mathrm{v}} 1.4$, Q14524 for $\mathrm{hNa}_{\mathrm{v}} 1.5$, Q15858 for $\mathrm{hNa}_{\mathrm{v}} 1.7$, Q9UI33 for $\mathrm{hNa} \mathrm{v}_{\mathrm{v}} 1.9$, P62520 for JZTX-III]. For JZTX-III related yeast-two -hybrid assays, the coding sequences of the extracellular regions (S1-S2 or S3-S4) of VGSCs were inserted to vector $\mathrm{pGADT}_{7}$ as the Preys, respectively (Supplementary Table S1). The coding sequence of JZTX-III was inserted to another vector $\mathrm{pGBKT}_{7}$ as Bait, using upper primer (5'-GGAATTCCATATGGTGTGCATGACCCGAACTGAT-3', Nde I) and lower primer 
(5'-GGAATTCTTAGACGTACTCGACTTTCTCTGG-3', EcoR I). For screening random-10-library assay, the coding sequences of extracellular regions of VGSCs were inserted to vector $\mathrm{pGBKT}_{7}$ as the bait.

Autonomous activation and interaction detecting assays were performed according to Yeast Protocols Handbook of Clontech. For JZTX-III related yeast-two-hybrid assays, interactions were detected using Colony-lift Filter Assay. For screening the random-10-library, interactions were identified using medium stringency selection media (-Leu/-Trp/-His)

Chimeras for electrophysiological assay, Random peptide library. Chimeras (Supplementary Table S2 and Table S3) for electrophysiological assays were obtained using the overlapped PCR mutation method described previously ${ }^{24}$. Random-10peptide library was constructed using insertion of a pair of random primers to vector $\mathrm{pGADT}_{7}$, including upper primer (5'-CGTACCAGATTACGCTNNKNNKNNKNNKNNKNNKNNKNNKNNKNNKTAATAGCCGGGTGGGCATCGATACGGGATCCAT- $3^{\prime}$ ) and lower primer (5' -ATGCCCACCCGGCTATTAMNNMNNMNNMNNMNNMNNMNNMNNMNNMNNAGCGTAATCTGGTACGTCGTATGGGTACTC- $3^{\prime}$ ), according to a method reported previously ${ }^{25}$. However, in order to harvest enough library plasmids, the cycles of PCR were 25-30 times which was much more than the method mentioned. $(\mathrm{N}=\mathrm{A}: \mathrm{T}: \mathrm{G}: \mathrm{C}=$ $25 \%: 25 \%: 25 \%: 25 \% ; \mathrm{K}=\mathrm{A}: \mathrm{T}: \mathrm{G}: \mathrm{C}=0: 50 \%: 50 \%: 0 ; \mathrm{M}=\mathrm{A}: \mathrm{T}: \mathrm{G}: \mathrm{C}=$ $50 \%: 0: 0: 50 \%)$

Whole-cell patch clamp assay. The whole-cell patch clamp assay was performed as previously described ${ }^{26,27}$. JZTX-III or SSCM-1 was dissolved to $1 \mathrm{mM}$ as stock solution using double distilled water, and aliquots were stored at $-20^{\circ} \mathrm{C}$. HEK293 cells were grown under standard tissue culture conditions $\left(5 \% \mathrm{CO}_{2} ; 37^{\circ} \mathrm{C}\right)$ in DMEM supplemented with $10 \%$ FBS. The $\beta 1$ and $\beta 2$ subunits were cotransfected with the $\mathrm{hNa}_{\mathrm{v}} 1.7$ channel to increase the current density. For $\mathrm{Na}_{\mathrm{v}}$ experiments on HEK293 cells, the pipette solution contained $140 \mathrm{mM} \mathrm{CsF}, 10 \mathrm{mM} \mathrm{NaCl}, 1 \mathrm{mM}$ EGTA and $10 \mathrm{mM}$ HEPES, pH 7.3; the bathing solution was $140 \mathrm{mM} \mathrm{NaCl}, 3 \mathrm{mM} \mathrm{KCl}, 1 \mathrm{mM}$ $\mathrm{MgCl}_{2}, 1 \mathrm{mM} \mathrm{CaCl}_{2}$, and $10 \mathrm{mM}$ HEPES, pH 7.3. For $\mathrm{Na}_{\mathrm{v}}$ experiments on DRG neurons, the pipette solution contained $145 \mathrm{mM} \mathrm{CsCl}, 4 \mathrm{mM} \mathrm{MgCl}_{2} \cdot 6 \mathrm{H}_{2} \mathrm{O}, 10 \mathrm{mM}$ HEPES, $10 \mathrm{mM}$ EGTA, $10 \mathrm{mM}$ Glucose, $2 \mathrm{mM} \mathrm{ATP} \mathrm{(pH} \mathrm{7.2);} \mathrm{the} \mathrm{bathing} \mathrm{solution}$ contained $145 \mathrm{mM} \mathrm{NaCl}, 2.5 \mathrm{mM} \mathrm{KCl}, 1.5 \mathrm{mM} \mathrm{CaCl}_{2}, 1.2 \mathrm{mM} \mathrm{MgCl}_{2} \cdot 6 \mathrm{H}_{2} \mathrm{O}$, $10 \mathrm{mM}$ HEPES, $10 \mathrm{mM}$ D-Glucose $(\mathrm{pH} 7.4)^{27}$. The whole-cell patch clamp assays were performed at room temperature $(25 \pm 2)$ using an EPC-10 amplifier (HEKA, Lambrecht, Germany). Data were analyzed using Pulsefit (HEKA) and Sigmaplot 10.0 (Systat Software Inc.) programs.

1. Dib-Haji, S. D. et al. Voltage-gated sodium channels in pain states: role in pathophysiology and targets for treatment. Brain Res Rev 60, 65-83, doi:10.1016/ j.brainresrev.2008.12.005 (2009).

2. Krafte, D. S. \& Bannon, A. W. Sodium channels and nociception: recent concepts and therapeutic opportunities. Curr Opin Pharmacol 8, 50-56, doi:S14714892(07)00163 -4 (2008).

3. Eijkelkamp, N. et al. Neurological perspectives on voltage-gated sodium channels. Brain 135, 2585-2612, doi:10.1093/brain/aws225 (2012).

4. Loffet, A. Peptides as drugs: Is there a market? J. Peptide Sci. 8, 1-7, doi:10.1002/ psc.366 (2002).

5. Mouhat, S., Andreotti, N., Jouirou, B. \& Sabatier, J.-M. Animal toxins acting on voltage-gated potassium channels. Curr Pharm Des. 14, 2503-2518, doi:10.2174/ 138161208785777441 (2008).

6. Estrada, G., Villegas, E. \& Corzo, G. Spider venoms: a rich source of acylpolyamines and peptides as new leads for CNS drugs. Nat. Prod. Rep. 24, 145-161, doi:10.1039/b603083c (2007).

7. King, G. F. Venoms as a platform for human drugs: translating toxins into therapeutics. Expert Opin Biol Ther 11, 1469-1484, doi:10.1517/ 14712598.2011.621940 (2011).

8. Klint, J. K. et al. Spider-venom peptides that target voltage-gated sodium channels: Pharmacological tools and potential therapeutic leads. Toxicon, doi:10.1016/ j.toxicon.2012.04.337 (2012).

9. Escoubas, P., Sollod, B. \& King, G. F. Venom landscapes: mining the complexity of spider venoms via a combined cDNA and mass spectrometric approach. Toxicon 47, 650-663, doi:S0041-0101(06)00038-9 (2006).

10. Fields, S. \& Song, O. A novel genetic system to detect protein-protein interactions. Nature 340, 245-246, doi:10.1038/340245a0 (1989).

11. Lentze, N. \& Auerbach, D. The yeast two-hybrid system and its role in drug discovery. Expert Opin Ther Targets 12, 505-515, doi:10.1517/14728222.12.4.505 (2008).

12. Catterall, W. A. From ionic currents to molecular mechanisms: the structure and function of voltage-gated sodium channels. Neuron 26, 13-25, doi:S08966273(00)81133-2 (2000).

13. Payandeh, J., Scheuer, T., Zheng, N. \& Catterall, W. A. The crystal structure of a voltage-gated sodium channel. Nature 475, 353-358, doi:10.1038/nature10238 (2011).
14. Rong, M. et al. Molecular basis of the tarantula toxin jingzhaotoxin-III (\{beta\}TRTX-Cj1\{alpha\}) interacting with voltage sensors in sodium channel subtype Nav1.5. FASEB J 25, 3177-3185, doi:fj.10-178848 (2011).

15. Bosmans, F., Puopolo, M., Martin-Eauclaire, M. F., Bean, B. P. \& Swartz, K. J. Functional properties and toxin pharmacology of a dorsal root ganglion sodium channel viewed through its voltage sensors. J Gen Physiol 138, 59-72, doi:10.1085/ jgp.201110614 (2011)

16. Chen, J. et al. Molecular diversity and evolution of cystine knot toxins of the tarantula Chilobrachys jingzhao. Cell Mol Life Sci 65, 2431-2444, doi:10.1007/ s00018-008-8135-x (2008).

17. Elliger, C. A. et al. Diversity of conotoxin types from Conus californicus reflects a diversity of prey types and a novel evolutionary history. Toxicon $\mathbf{5 7}, 311-322$, doi:10.1016/j.toxicon.2010.12.008 (2011).

18. Quintero-Hernandez, V. et al. Scorpion and spider venom peptides: gene cloning and peptide expression. Toxicon 58, 644-663, doi:10.1016/j.toxicon.2011.09.015 (2011).

19. Soong, T. W. \& Venkatesh, B. Adaptive evolution of tetrodotoxin resistance in animals. Trends Genet 22, 621-626, doi:S0168-9525(06)00276-9 (2006).

20. Bosmans, F. \& Tytgat, J. Voltage-gated sodium channel modulation by scorpion alpha-toxins. Toxicon 49, 142-158, doi:10.1016/j.toxicon.2006.09.023 (2007)

21. Doyle, D. A. et al. The structure of the potassium channel: molecular basis of $\mathrm{K}+$ conduction and selectivity. Science 280, 69-77 (1998).

22. King, G. F. Modulation of insect $\mathrm{Ca}(\mathrm{v})$ channels by peptidic spider toxins. Toxicon 49, 513-530, doi:10.1016/j.toxicon.2006.11.012 (2007).

23. Xiao, Y. et al. Jingzhaotoxin-III, a novel spider toxin inhibiting activation of voltage-gated sodium channel in rat cardiac myocytes. JBC 279, 26220-26226, doi:10.1074/jbc.M401387200 (2004)

24. Liu, H. \& Naismith, J. H. An efficient one-step site-directed deletion, insertion, single and multiple-site plasmid mutagenesis protocol. BMC Biotechnol 8, 91, doi:1472-6750-8-91 (2008).

25. Zheng, L., Baumann, U. \& Reymond, J. L. An efficient one-step site-directed and site-saturation mutagenesis protocol. NAR 32, e115, doi:10.1093/nar/gnh110 (2004).

26. Xiao, Y. et al. Tarantula huwentoxin-IV inhibits neuronal sodium channels by binding to receptor site 4 and trapping the domain ii voltage sensor in the closed configuration. JBC 283, 27300-27313, doi:10.1074/jbc.M708447200 (2008).

27. Wang, M., Guan, X. \& Liang, S. The cross channel activities of spider neurotoxin huwentoxin-I on rat dorsal root ganglion neurons. BBRC 357, 579-583, doi:S0006-291X(07)00373-7 (2007).

\section{Acknowledgments}

This work was supported by the Ministry of Science and Technology of China "973" Project (No. 2010CB529800), National Natural Science Foundation of China (No. 3097142, 11004246, and 31100609), New Century Excellent Talents in University (No. NCET-05-0715), and NUDT University Project (No. JC2006-02-01).

\section{Author contributions}

D.-Y.Z. and E.M. designed the appropriate technology routes. E.M. and T.-F.C. conducted main experiments including cloning, random-10-peptie library, yeast-two-hybrid, and whole-cell patch clamp assays. H.Z., S.T. and M.-J.L. participated in random-10-peptide library. W.-Y.L., L.L., L.W. and L.-Y.Z. participated in building constructs. P.-F.H., K.L. and K.P. participated in whole-cell patch clamp. X.-D.D., H.J. and X.-Z.Z. performed the mass spectrometry and contributed to chemical synthesis and purification of SSCM-1. D.-Y.Z. and S.-P.L. supervised the project and wrote the paper. All authors read and approved the final manuscript.

\section{Additional information}

Supplementary information accompanies this paper at http://www.nature.com/ scientificreports

Competing financial interests: The authors declare no competing financial interests.

How to cite this article: Meng, E. et al. Screening for Voltage-Gated Sodium Channel Interacting Peptides. Sci. Rep. 4, 4569; DOI:10.1038/srep04569 (2014).

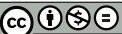

This work is licensed under a Creative Commons Attribution-NonCommercialNoDerivs 3.0 Unported License. The images in this article are included in the article's Creative Commons license, unless indicated otherwise in the image credit; if the image is not included under the Creative Commons license, users will need to obtain permission from the license holder in order to reproduce the image. To view a copy of this license, visit http://creativecommons.org/licenses/by-nc-nd/3.0/ 